\title{
2-2016
}

\section{Assessing the Risk of Atrocity Crimes}

\author{
Adama Dieng \\ United Nations Special Adviser on the Prevention of Genocide \\ Jennifer Welsh \\ United Nations Special Adviser on the Responsibility to Protect
}

Follow this and additional works at: https://digitalcommons.usf.edu/gsp

\section{Recommended Citation}

Dieng, Adama and Welsh, Jennifer (2016) "Assessing the Risk of Atrocity Crimes," Genocide Studies and Prevention: An International Journal: Vol. 9: Iss. 3: 4-12.

DOI:

http://dx.doi.org/10.5038/1911-9933.9.3.1392

Available at: https://digitalcommons.usf.edu/gsp/vol9/iss3/4

This Special Contribution is brought to you for free and open access by the Open Access Journals at Digital Commons @ University of South Florida. It has been accepted for inclusion in Genocide Studies and Prevention: An International Journal by an authorized editor of Digital Commons @ University of South Florida. For more information, please contact digitalcommons@usf.edu. 
Assessing the Risk of Atrocity Crimes

\author{
Adama Dieng \\ United Nations Special Adviser on the Prevention of Genocide \\ Jennifer Welsh \\ United Nations Special Adviser on the Responsibility to Protect
}

\title{
Background
}

The Framework of Analysis for Atrocity Crimes is a tool developed by the United Nations Office on Genocide Prevention and the Responsibility to Protect to guide the assessment of the risk of atrocity crimes ${ }^{1}$ worldwide. This document builds upon the previous Framework of Analysis for the risk of genocide that was developed in 2009 by the then United Nations Office of the Special Adviser on the Prevention of Genocide, in order to fulfil its early warning mandate. That tool was based on the foundation laid by former United Nations Secretary-General Kofi Annan when he launched his plan of action to prevent genocide in April 2004. In the Secretary-General's words on that occasion:

\begin{abstract}
If we are serious about preventing or stopping genocide in the future, we must not be held back by legalistic arguments about whether a particular atrocity meets the definition of genocide or not. By the time we are certain, it may often be too late to act. We must recognize the signs of approaching or possible genocide, so that we can act in time to avert it. We badly need clear guidelines on how to identify such extreme cases and how to react to them. Such guidelines would ensure that we have no excuse to ignore a real danger of genocide when it does arise.
\end{abstract}

The initial framework of analysis for the prevention of genocide became obsolete when, in 2010, the Secretary-General decided to link the complementary mandates of the Special Advisers on the Prevention of Genocide and on the Responsibility to Protect through a joint office. Since then, the early warning work undertaken by this office has covered the risk not only of genocide but also of war crimes, ethnic cleansing and crimes against humanity.

The present Framework thus provides an integrated analysis and risk assessment tool for genocide, war crimes, ethnic cleansing and crimes against humanity. The revision also reflects recent developments and new research into the processes that lead to these crimes. It was subject to consultations within and outside the United Nations system for a period of almost two years. The result is a Framework that serves as a working tool for the assessment of the risk of atrocity crimes in all parts of the world and for identifying those countries most at risk. It can be used to develop a basic risk assessment, as well an assessment of how a situation is changing over time and the kinds of events that can trigger change, or prevent a situation from deteriorating.

The Framework is based on the premise that, to be effective, assessments require the systematic collection of accurate and reliable information based on a number of risk factors and indicators. The broad risk factors and the more specific indicators reflect definitions of the crimes in international law, case law from the work of international courts or tribunals, and empirical analysis of past and present situations.

The elements required to assess the risk of genocide and crimes against humanity are directly influenced by the legal definition of these crimes. With respect to war crimes and ethnic cleansing, however, the approach is slightly different. First, given the absence of a conceptual definition common to all war crimes, such as that which exists in the case of genocide and crimes against humanity, the Framework focuses on those war crimes that have the greatest impact on the protection of human life. In addition, given the focus of the Responsibility to Protect on the protection of populations from the most serious violations of international human rights and humanitarian law, the Framework covers war crimes that assume a more systematic or widespread pattern of conduct. Second, given that ethnic cleansing does not have a distinct legal definition as

${ }^{1}$ The Office uses the term atrocity crimes to refer to the crimes of genocide, crimes against humanity and war crimes, as well as to ethnic cleansing even though the latter does not constitute an independent crime under international law. 
an international crime, but includes acts that can constitute other atrocity crimes or elements of them, it has been integrated into the analysis of the risk factors for those crimes.

This Framework is a public document. The Office encourages and welcomes its use by international, regional and national actors as a tool either for early warning mechanisms, or for other mechanisms used for monitoring, assessment and forecasting. In addition, the Office recommends that Member States use the Framework to help identify both areas of success as well as gaps in atrocity prevention capacities and strategies at the national level. In the foreword of the document, the United Nations Secretary-General urges Member States, United Nations colleagues, civil society actors, media, and all persons dedicated to prevention and protection efforts, to disseminate and make use of this tool. In the end, sounding the alarm, mobilising preventive action and promoting resilient societies constitute tasks for all of us.

\section{Common and Specific Risk Factors}

This Framework defines risk factors as the conditions that increase the risk of or susceptibility to negative outcomes. They include behaviours, circumstances or elements that create an environment conducive to the commission of atrocity crimes, or indicate the potential, probability or risk of their occurrence. This requires assessment of a range of factors related not only to the risk of armed conflict but also to other types of situations that put a State under stress and create an environment conducive for atrocity crimes to occur. This means, for example, looking at the capacities and motivations of potential perpetrators; monitoring the human rights situation; assessing strengths and weaknesses of key state institutions; identifying gaps in societal resilience, or sources of mitigation; and anticipating a variety of possible triggers.

Risk factors are not all the same. Some are structural in nature, such as the weakness of State institutions, while others pertain to more dynamic circumstances or events, such as triggering factors. Triggers and other dynamic elements transform general risk into an increased likelihood that atrocities crimes will be committed. The indicators included in this framework are different manifestations of each risk factor, and therefore assist in determining the degree to which an individual risk factor is present. The particular indicators identified in the Framework have been drawn from past and current cases, but are not intended to be exhaustive.

In summary, the Framework contains two main analytical tools for assessing the risk of atrocity crimes: (a) a list of fourteen risk factors for atrocity crimes; and (b) indicators for each of the risk factors.

Among the fourteen risk factors outlined, the first eight are common to all crimes, reflecting the fact that atrocity crimes tend to occur in similar settings and share several elements or features. They are: (1) situations of armed conflict or other forms of instability; (2) record of serious violations of international human rights and humanitarian law; (3) weakness of State structures; (4) motives and Incentives; (5) capacity to commit atrocity crimes; (6) absence of mitigating factors; (7) enabling circumstances or preparatory action; (8) triggering factors.

In addition to these common factors, the Framework identifies six additional risk factors, two specific to each of the international crimes - namely genocide, crimes against humanity and war crimes. The risk factors specific to the crime of genocide are: (9) intergroup tensions or patterns of discrimination against protected groups; and (10) signs of intent to destroy in whole or in part a protected group. The risk factors specific to crimes against humanity are: (11) signs of a widespread or systematic attack against any civilian population; and (12) signs of a plan or policy to attack any civilian population. The risk factors specific to war crimes are: (13) serious threats to those protected under international humanitarian law; and (14) serious threats to humanitarian or peacekeeping operations. The chart on the next page provides a summary of risk factors and indicators.

The common risk factors are aimed at supporting the identification of the probability of atrocity crimes overall, without necessarily identifying the type of crime. The assumption is that in the initial stages of monitoring, it is not always possible to identify which specific crime is most at risk. This becomes clearer as the process leading to atrocity crimes progresses. For example, weak State structures put populations or groups at risk of any of these crimes. In addition, different kinds of atrocity crimes can occur concurrently in the same situation, or one crime might be a precursor to another form of atrocity crime. 


\section{COMMON RISK FACTORS}

Risk Factor 1 Situations of armed conflict or other forms of instability

Risk Factor 2 Record of serious violations of international human rights and humanitarian law

Risk Factor 3 Weakness of State structures

Risk Factor 4 Motives or incentives

Risk Factor 5 Capacity to commit atrocity crimes

Risk Factor 6 Absence of mitigating factors

Risk Factor 7 Enabling circumstances or preparatory action

Risk Factor 8 Triggering factors

\section{SPECIFIC RISK FACTORS}

Genocide

Risk Factor 9 Intergroup tensions or patterns of discrimination against protected groups

Risk Factor 10 Signs of an intent to destroy in whole or in part a protected group

Crimes Against Humanity

Risk Factor 11 Signs of a widespread or systematic attack against any civilian population

Risk Factor 12 Signs of a plan or policy to attack any civilian population

War crimes

Risk Factor 13 Serious threats to those protected under international humanitarian law

Risk Factor 14 Serious threats to humanitarian or peacekeeping operations

The specific risk factors, on the other hand, result from the fact that each crime has elements and precursors that are not common to all three crimes. This is clear in the elements that are specific to the crime of genocide, particularly the intent to destroy, in whole or in part, a national, ethnical, racial or religious group. The evidence of such intent points to a higher risk of genocide. In this way, the specific risk factors identified in the framework reflect the legal definitions of the crimes, even though they are not strictly limited by them, nor intend to be criminal evidence of them.

The risk factors are elaborated as follows:

1. Situations of armed conflict or other forms of instability

Atrocity crimes often take place against a background of either an international or noninternational armed conflict. Armed conflicts are periods characterized by a high incidence of violence, insecurity and the permissibility of acts that would otherwise not be acceptable. In addition, the capacity of States to inflict harm is usually at its peak during periods of conflict. If armed conflict is a violent way of dealing with problems, it is clear that the risk of atrocity crimes acutely increases during these periods. However, other situations that do not constitute formal armed conflicts can also put a State under such a level of stress that it becomes more prone to serious human rights violations and, eventually, to atrocity crimes. In fact, genocide and crimes against humanity can also occur during times of peace. This is most likely when there are serious levels of political instability, threats to the security of the country or even volatility in economic or social affairs. Although situations of instability, or even of armed conflict, will not necessarily lead to the occurrence of atrocity crimes, they highly increase the likelihood of those crimes. 
2. Record of serious violations of international human rights and humanitarian law

Societies that have already experienced serious violations of international human rights and humanitarian law or atrocity crimes, or where these are currently taking place, can be more prone to further atrocity crimes. As history has demonstrated, atrocity crimes in general and genocide in particular are preceded by less widespread or systematic serious violations of international human rights and humanitarian law. These are typically violations of civil and political rights, but they may include also severe restrictions to economic, social and cultural rights, often linked to patterns of discrimination or exclusion of protected groups, populations or individuals. This risk factor is also relevant where the legacies of past atrocity crimes have not been adequately addressed through individual criminal accountability, reparation, truth-seeking and reconciliation processes, as well as comprehensive reform measures in the security and judicial sectors. A society in this situation is more likely to resort again to violence as a form of addressing problems.

\section{Weakness of State structures}

The risk of atrocity crimes can be increased by a State's lack of capacity to prevent these crimes. A State protects its population through the establishment of frameworks and institutions that are guided by the rule of law and good governance principles. However, when such structures are inadequate or simply do not exist, the ability of the State to prevent atrocity crimes is significantly diminished. As a consequence, populations are left vulnerable to those who may take advantage of the limitations or the dysfunction of State machinery, or to those that may opt for violence to respond to real or perceived threats. This is even more the case in a situation of armed conflict, when it is paramount that those resorting to the use of force are fully aware of and respect the rules that aim to protect populations from such force, and have the necessary means to do so. The weakness of State structures will not necessarily be a cause of atrocity crimes, but it undoubtedly decreases the level of protection and, when analysed in conjunction with other risk factors, increases the probability of atrocity crimes.

\section{Motives or incentives}

The motives or incentives that lead perpetrators to commit atrocity crimes are not elements of the legal definition of those crimes and are therefore not relevant to determine individual criminal responsibility. However, from an early warning perspective, it is extremely important to identify motivations, aims or drivers that could influence certain individuals or groups to resort to massive violence as a way to achieve goals, feed an ideology or respond to real or perceived threats. Doing so not only allows for a higher degree of prediction of the likelihood of those crimes, but also opens up the opportunity to develop prevention strategies aimed at neutralizing or curbing those motives or incentives. No one specific motive or incentive will automatically lead to atrocity crimes, but certain motives or incentives are more likely to do so, especially those that are based on exclusionary ideology or the the construction of binary identities of "us" and "them".. The historical, political, economic or even cultural environment in which such ideologies develop can also be relevant.

\section{Capacity to commit atrocity crimes}

The systematic and large-scale violence that marks atrocity crimes requires a substantial level of planning that, in most cases, is sustained over a period of time. To be able to engage in such conduct, actors aiming at committing atrocity crimes must have at their substantial resources and support, either internal or external. However, the fact that States or groups have the capacity to perpetrate atrocity crimes does not imply that they will commit them - for that, it is also necessary that they have the intention to make use of that capacity against a protected group, population or individual. . In contrast, those who do not have the capacity to commit atrocity crimes, i.e., where one or more of the indicators 
mentioned above are not present, will most likely not be able to put any plan into action, or will face serious challenges in its attempt to implement it.

6. Absence of mitigating factors

Atrocity crimes result from a convergence of elements, as demonstrated in this framework. Among those elements, some point more directly to the likelihood of atrocity crimes, while others might have a more indirect effect and seem secondary, or even too broad to merit consideration. However, even if indirect, these elements can contribute to preventing an escalation of violence or even to ending it and can therefore reduce the probability of atrocity crimes. Presence of strong and representative civil society organizations; operation of free, diverse and independent media; and access to the country by international or regional actors, constitute examples of factors that can mitigate the risk of commission of atrocity crimes. While some of these elements can exist prior to the development of tensions, crises or conflict, their impact may weaken as a situation escalates. It is therefore important to strengthen mitigating factors as a way of increasing resilience against the risk of atrocity crimes. A determination of the strength of mitigating factors in each given situation is also essential for early warning purposes.

\section{Enabling circumstances or preparatory action}

Atrocity crimes, and in particular genocide and crimes against humanity, are processes that take time to plan, coordinate and implement. The creation of militias, imposition of emergency laws or acquisition of large quantities of ammunition, which we consider as indicators in this risk factor, constitute steps that could point to preparatory action. Atrocity crimes, therefore, cannot be explained as isolated or spontaneous events that perpetrators decided to commit without some level of preparation. As mentioned in connection to risk factor n.5 (capacity to commit atrocity crimes), perpetrators also need to possess sufficient resources to be able to commit massive or widespread acts of violence. . It is possible to identify events, actions or changes that point to the likelihood that certain actors are taking steps towards a scenario of mass violence and possibly atrocity crimes. Such events, actions or changes can also serve to create an environment that favours or even encourages the commission of such crimes. Recognizing such indicators and establishing a causal link to the probability of atrocity crimes is not always easy, but it is of great relevance. As with all risk factors, analysis of this risk factor should take into consideration a context in which other risk factors might also be present.

8. Triggering factors

The dynamics of atrocity crimes are not the same in all cases. In fact, they can vary considerably. The commission of atrocity crimes may progress at a faster pace if the perpetrators have a clear plan and the immediate capacity to implement it. In other situations, the commission of atrocity crimes might unfold at a late stage of a situation of on ongoing crisis. It may also be that unpredictable events or circumstances aggravate conditions or spark a sudden deterioration in a situation, prompting the perpetration of atrocity crimes. This is particularly the case for on-going armed conflicts. An adequate early warning assessment should thus be mindful of all such events or circumstances and consider their potential impact, even if they appear to be unrelated to more direct or structural risk factors.

Risk factors that are specific for each of the crimes are as follows:

9. Intergroup tensions or patterns of discrimination against protected groups (genocide) Genocide is an extreme form of identity-based crime. Whether real or socially constructed, identity can be subject to manipulation by elites, including as a deliberate tactic for personal or political gain, and may be used to deepen societal divisions. Identity-based conflict, which may give rise to the crime as defined by the Convention on the Prevention 
and the Punishment of the Crime of Genocide, can be rooted in differences between national, ethnical, racial or religious groups, whether real or perceived. It can also be rooted in other differences, such as those of a political or even geographical nature, that eventually develop along national, ethnical, racial or religious lines. However, the risk factor is not the existence of diversity within the population of a country, nor is it those differences per se that cause conflict between groups. Instead, it is discrimination based on such differences, and persistent patterns of it, that establish divisions within society which serve as both a material cause and a perceived justification of group violence. Without group-level discrimination, even deeply seated grievances are unlikely to transform into the patterns of abuse that give rise to genocide.

10. Signs of an intent to destroy in whole or in part a protected group (genocide)

The intent to destroy in whole or in part a national, ethnical, racial or religious group is both one of the most fundamental and one of the most difficult elements of the crime of genocide to prove. It is also a challenging element to predict from an early warning perspective. Frequently, the intent only comes to light after a crime has taken place, typically during accountability processes, or sometimes when it might be too late to take preventive action due to the advanced level of the violence. However, there are some early indicators that can serve as a warning sign. Those indicators are unlikely to be explicit, but they can also be inferred from conduct that would reasonably lead to the belief, even if not the certainty, that the intent of or a plan for annihilation could exist. Indicators can include overt methods of destruction, or otherwise covert or indirect methods that in practice lead to the same ultimate result. In addition, case law has associated intent with the existence of a State or organizational plan or policy, even if the definition of genocide in international law does not include that element. As genocide is not a spontaneous act, it is unlikely that it will be committed in the absence of such a plan or policy.

11. Signs of a widespread or systematic attack against any civilian population (crimes against humanity)

Crimes against humanity involve either large-scale violence (quantitative element) or a methodical type of violence (qualitative element). This excludes random, accidental or isolated acts of violence that, in addition, could be difficult to predict. Instead, the type of violence that characterizes crimes against humanity will most probably require a level of preparation that can be revealed through different indicators. Such indicators can, for example, relate to the means and methods used to engage in violence, or to patterns of violent conduct during the early stages of a conflict that can help predict an aggravation of those patterns and, consequently, the potential for crimes against humanity. Other indicators can point to patterns of conduct - even outside of a conflict situation - that manifest earlier, such as the building up of capacity for large-scale or systematic violence, or the use of alternative means to target civilian populations or particular groups within them. Identifying early stages of pattern manifestation is crucial to be able to devise strategies to stop them.

12. Signs of a plan or policy to attack any civilian population (crimes against humanity) In addition to the requirement that attacks against the civilian population be widespread or systematic, crimes against humanity are committed in furtherance of a State or organizational policy. Even though this is not included in the definition of the crime under Article 7(1) of the Rome Statute, Article 7(2)(a) of the same document introduces this element. The plan or policy does not need to be explicitly stipulated or formally adopted and can, therefore, be inferred from the totality of the circumstances. Early signs of those circumstances, such as the indicators mentioned above, reveal planning, promotion or encouragement of violent acts, even if not explicitly presented as such. Conduct that manifests as widespread or systematic, as described in the previous risk factor, can be an indication of a plan or policy. On the other hand, a plan or policy can 
point to the systematic nature of an attack. The distinction between both might not always be clear.

13. Serious threats to those protected under international humanitarian law (war crimes) In contrast to the crimes of genocide and crimes against humanity, war crimes always take place in the context of an armed conflict. Consequently, indicators specific to war crimes surface at a late stage, when options for prevention are more limited. For earlier preventive action, common risk factors should be considered first. However, even if a conflict is already under way, there are still measures that can be taken to diminish the effects of hostilities and, therefore, to prevent war crimes. The list of war crimes is long and each has a specific definition. They can also vary according to different norms of international law. The indicators identified above attempt to include indicators relevant to as many war crimes as possible that are related to the protection of human life. However, they are far from exhaustive. Some of the indicators identified can also on their own be war crimes, such as attacks against civilian property, which can point to an increase in the threat to human life.

14. Serious threats to humanitarian or peacekeeping operations (war crimes)

International humanitarian law affords specific protection to those working for humanitarian assistance or peacekeeping missions in a setting of armed conflict, as long as they do not take direct part in hostilities, except for self-defense. These operations are particularly exposed to the violence that accompanies periods of conflict due to the key role they play in the protection of human lives and the alleviation of human suffering during those periods. A set of specific indicators can help in assessing the likelihood of attacks against this group that could constitute war crimes. As the focus of the Framework is the protection of human life, attacks against property of humanitarian or peacekeeping operations have been included only as indicators of an increased risk to the lives of their staff.

\section{Methodology of Use}

Assessments of the risk of atrocity crimes must be flexible and sensitive to context. Five points are particularly important to bear in mind when using the Framework.

First, not all risk factors need to be present for there to be an assessment that there is a significant risk of atrocity crimes occurring. For example, there are situations where information gathered has confirmed the presence of most of the risk factors, but atrocity crimes have not yet taken place. This could be due to the absence of a triggering event or the presence of a strong mitigating factor. In addition, it may not be possible to obtain sufficiently accurate and reliable information to confirm the presence of a particular risk factor. Nevertheless, this should not deter monitors and analysts from warning of the likelihood that an atrocity crime could be committed. Triggering factors are not always predictable and a strong mitigating factor might weaken or disappear. It is also important to bear in mind that common risk factors tend to be manifest sooner than specific risk factors. Information that confirms the presence of specific risk factors is sometimes more difficult to obtain at an early stage.

Second, the more risk factors (and the greater number of relevant indicators) there are present, the greater the risk that an atrocity crime may be committed. Also, the greater the number of indicators of a particular risk factor that are present, the greater the importance and role of that factor in a particular situation. For instance, a situation that presents motives and incentives (risk factor 4) and in which there is weakness of State structures (risk factor 3), is more prone to commission of atrocity crimes if there is context of armed conflict or other forms of stability (risk factor 1) and an absence of mitigating factors (risk factor 6). In this example, the absence of risk factors 1 and 6, in principle, would lower the risk of atrocity crimes. Likewise, we can assume that weakness of State structures (risk factor 3) is more pronounced if all indicators within that risk factor are present than if only some are. For instance, the presence of a weak national legal 
protection framework becomes a stronger indicator if it is coupled with lack of independent and impartial judiciary or with high levels of corruption. If the judiciary is impartial and corruption is not rampant, the impact of a weak legal protection system - for purpose of risk of atrocity crimes - is less pronounced.

Third, the risk factors and the indicators are not ranked, as their relative importance will differ according to the particular context. Even though armed conflict has been identified as the strongest or most important contributing risk factor, armed conflict is not a precondition of all atrocity crimes - genocide and crimes against humanity can also occur in times of peace. Certainly, some risk factors will have a greater weight than others, or will be manifest more often than others. However, all contribute to increasing the risk of atrocity crimes.

Fourth, monitors and analysts will need to be flexible when considering and weighing all the elements in this Framework and situate them within a broader political, contextual, historical and cultural analysis. In addition, given the development of new trends and patterns of violence and of conduct related to conflict, assessments should be open to new elements that might surface.

Finally, the Framework of Analysis provides a set of elements to help monitors make qualitative and systematic assessments of the risk of atrocity crimes in specific situations. However, the presence of risk factors for atrocity crimes in a particular situation does not automatically lead to the occurrence of those crimes; risk is not equated with inevitability. Sometimes, even when several risk factors are present, a situation may not escalate to the point where atrocities will be committed. That said, and although it is impossible to draw a direct causal relation between the presence of particular risk factors and the occurrence of atrocity crimes, these crimes are rarely committed in the absence of all or most of the risk factors that the Framework identifies.

\section{The Framework as a Tool for Early Action}

While the Framework constitutes primarily a tool for analysis, it has also been designed to facilitate early action. The assumption is that a systematic application of the Framework will contribute to the identification of situations of concern and to sound the alarm earlier and more consistently. In this regard, both States and the international community must assume their legally established responsibilities to respond to these alarms and to protect populations against atrocity crimes before they occur. The Framework, in short, aims at compelling actors to move from early warning to early action

The Framework recognizes that atrocity crimes do not usually constitute single or random events. Instead, they tend to develop in a dynamic process that offers entry points for action to prevent their occurrence. To engage in the level of violence associated with atrocity crimes, perpetrators need time to develop the capacity to do so, mobilize the resources, and take concrete steps that will help them to achieve their objectives. If the risk factors and precursors of these crimes are understood, it follows that it is also possible to identify measures that can be taken by States and the international community to forestall the dynamics that lead to these crimes.

In sum, the earlier the risk factors are identified, the greater the opportunities for early and preventive action. As times goes on, such action becomes more difficult and more costly. As experience shows, if atrocity crimes are already occurring, the options available to respond will be very limited. In some cases, they may require the use of coercive measures including, if all peaceful means fail, the use of force.

Atrocity crimes have wide-ranging costs and long-lasting effects. Painful experience over the past decades illustrates how the perpetration of violence based on the victims' identity destroys the fabric of societies, with consequences that pass from one generation to the next. As the United Nations Secretary-General underlined in his 2015 report on the responsibility to protect, it is imperative that Member States and other international actors devote more energy and resources to effective prevention and accelerate efforts to put an end to the ongoing perpetration of such crimes.

We consider that the Framework of Analysis for Atrocity Crimes constitutes a tool to facilitate accurate assessment and identify options for adequate and effective response. We encourage it to be used by all those who are devoted to the principle of prevention and whose contribution and response can be essential for the prevention of atrocity crimes. 


\section{Note}

The views expressed herein are those of the author(s) and do not necessarily reflect the views of the United Nations. 